\title{
Urinary System Findings Reference Identifier
}

National Cancer Institute

\section{Source}

National Cancer Institute. Urinary System Findings Reference Identifier. NCI Thesaurus.

Code C162209.

A character or string that represents a urinary system findings event reference. 